\title{
Review
}

\section{HIV Infection a Social and a Healthcare Problem}

\author{
Antonella Chesca ${ }^{1}$ and Tim Sandle ${ }^{2}$
}

\author{
${ }^{1}$ Transilvania University of Brasov, Romania \\ ${ }^{2}$ University of Manchester, United Kingdom
}

Corresponding author:

Antonella Chesca, Transilvania University of Brasov,

E-mail: anto.chesca@gmail.com

\begin{abstract}
HIV infection invariably attracts the attention of medical staff in complex medical specialties. To achieve the goal of elimination by 2020, various approaches are required, including the establishment of prevention, diagnosis, monitoring, treatment, control measures. These should be supported by statistical studies that report on restricted or extended geographical areas, to the level of social class and age. Such an approach, combing the medical and social science perspectives (medicosocial) can prove useful for developing control measures. Due to the complexity of this immunodeficiency pathology, the condition also attracts comorbidities (most notably tuberculosis). Hence, prospective strategies need to be developed and oriented towards the goal of eradicating HIV infection. This paper presents strategies for consideration.
\end{abstract}

Key words: HIV, approach, strategies, patient, methodologies 


\section{Introduction}

Immunodeficiency occurs during the course of the disease in HIV-infected patients and this leads to specific clinical pictures that need to be recognized to ensure the correct treatment is administered. In this context, such symptoms also need to be considered because they may raise the suspicion of a possible adjacent infection [1]. From this point of view, establishing an early diagnosis is essential [2]. This has implications for the course of the disease, as well as HIV transmission to people who are seronegative [3].

Regarding the management of HIV / AIDS infection, the number of co-infections that change the evolution of the disease, as indicated from the growing number of studies, has increased (notably tuberculosis, which is discussed below). In this regard, the establishment of measures to prevent HIV infection and co-infections remain important [4]. 
<smiles>CCC(C)[C@H](NC(=O)C(Cc1ccccc1)NC(=O)[C@H](CCC(N)=O)NC(=O)[C@H](N)CCCCN)C(=O)N[C@@H](CC(N)=O)C(=O)N[C@@H](CCSC)C(=O)N[C@@H](Cc1c[nH]c2ccccc12)C(=O)NC(CCC(N)=O)C(=O)N[C@@H](CCC(=O)O)C(=O)N[C@@H](C(=O)NCC(=O)N[C@@H](CCCCN)C(=O)N[C@@H](C)C(=O)N[C@@H](CCSC)C(=O)N[C@@H](Cc1ccc(O)cc1)C(=O)N[C@@H](C)C(=O)N1CCC[C@H]1C(=O)N1CCOC1=O)C(C)C</smiles>

HIV (GP120) FRAGMENT (421-438)

According to the WHO, the vulnerability of certain populations within a given society is a key point and this vulnerability is enhanced by limited by access to HIV testing and counseling. This is particularly noticeable among populations at high risk of HIV infection within the European region, who often reside in more deprived communities. In this context, a second vulnerable target group is represented by adolescents and young people, because they are considered the most exposed to discrimination, stigma, and violence [5]. 


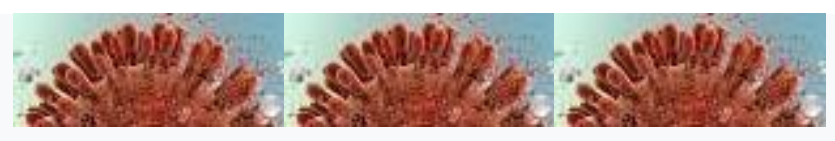

Figure 1. HIV fragments

Research in the field has helped to improve the quality of life of HIV-infected patients, and has also helped to improve treatment for this condition. This is reflected in different types of therapies, from therapies used for infected patients with resistant strains of the virus, and to the newest, developing therapies, which involve genetic editing [6].

Given recent studies and complex approaches to HIV infection and the results obtained in recent years, the United Nations Program on HIV / AIDS (UNAIDS) has adopted the goal of eliminating the global epidemic by 2030. In this context, we analyze how this goal can become the reality [7]. The challenge is with reaching out, educating and supporting, target populations. For this, a medioscoial approach is required.

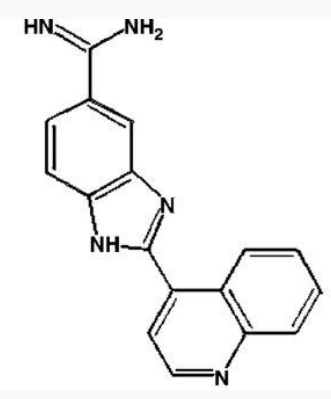

Compound 1, an inhibitor of HIV-1 integrase generated from within the diversity space by the de novo drug design program.

The World Health Organization, knowing the limits of measuring the health of a population, including those related to the spread of HIV, estimates that the real incidence cannot be accurately calculated within a given territory [8]. Instead, the World Health Organization has 
shown that the assessment of the health status of patients diagnosed with HIV can best be estimated based on the registration of cases and epidemiological models. Therefore, a calculation model is used to deduce the detection rate, which estimates the percentage of registered cases compared to the estimated number of existing cases $[9,10]$.

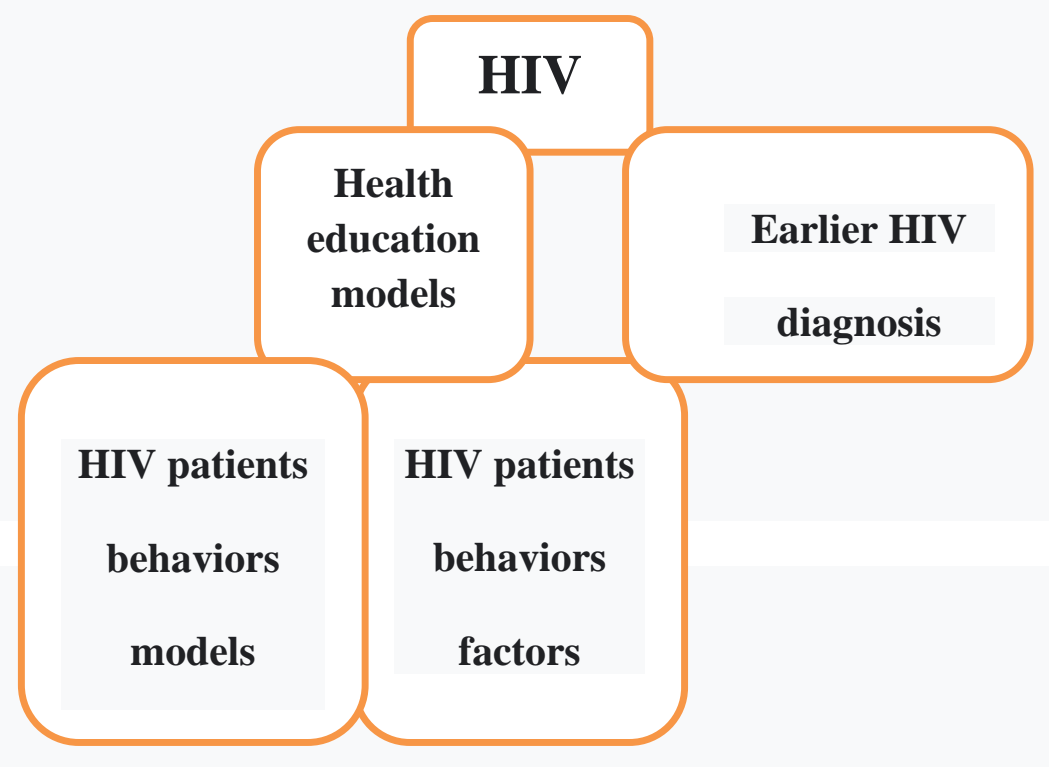

\section{Health education models}

Health education models have focused heavily on transmitting information in the hope that the message will be internalized, operationalized, and transferred to behavioral levels by the target group. From current practice, however, the results of studies have shown that essentially rational ways of persuasion have often been opposed by resistance and irrational reactions $[11,12]$. From another perspective, it is noted that the significant influence on the trends of mortality and morbidity related to the position of individuals in the social hierarchy. In this context, the researchers pointed out in their writings that the differences between social classes in the structure of morbidity are explained by a high level of education that attracts large financial 
resources $[13,14]$. From this point of view, it is appreciated that more educated people are defined by lifestyles that allow them to resort more frequently to medical services to take care of their health. On the other hand, people belonging to disadvantaged social classes, defined by the lack of resources, are also characterized by values that explain the low addressability of medical services [15].

The Joint Action on HIV and Coinfection Prevention and Harm Reduction (HA-REACT) are considered priorities for addressing gaps in the prevention of HIV and co-infections such as HIV-TB / viral hepatitis. The ECDC (European Center for Disease Prevention and Control) also emphasized the need to diagnose HIV in the early stages of the disease. In this context, statistics show that HIV infection is typically diagnosed 3 years after onset. (16) At the same time, it has been shown that in the EU / EEA, in $68 \%$ of cases, the diagnosis of AIDS are made 3 months after the identification of HIV infection. The results of the studies and the statistics showed that the early diagnosis of HIV infection leads to increased life expectancy and will also help to prevent the transmission of the virus $[17,18]$.

\section{Earlier HIV diagnosis}

It is also considered that establishing an early diagnosis is important because it allows people affected by the immunodeficiency virus to start anti-HIV treatment earlier. (19)From this point of view, patients have the chance to live a longer and healthier life. These patients are associated with the provision of HIV counseling and testing services, including rapid diagnostic services, community-based HIV testing, and HIV self-testing. With voluntary HIV testing and counseling (HTC), it is important that these are made available both in the clinical setting and in the community, since these are seen as a vital component of prevention, treatment, and care services. It is especially important that vulnerable populations living with HIV have access to 
antiretroviral therapy [20]. Also, all pregnant women in vulnerable populations should have the same access to services during pregnancy, to prevent mother-to-child transmission of HIV. Ensuing compliance with the treatment of patients diagnosed with HIV is important. From this point of view, patients who are not adherents to therapy, or those who have additional medical or social problems, can affect public health in a society. In connecting HIV to another infection of concern, and one also associated with deprived communities, HIV-TUBERCULOSIS (TB) is a major risk of death in HIV-positive people. In this context, it was recorded in the statistical results that one in three AIDS-related deaths had TB. At the same time, the results of the statistics showed that people living with HIV without symptoms of TB need preventive anti-TB therapy, which reduces the risk of TB / HIV mortality by about $40 \%$. The failure of a treatment against this bacterial infection has detrimental consequences on the patient, with consequences for public health and implicitly for society.

Due to limited access to anti-HIV treatment in many countries, especially in Eastern Europe, there is an increase in the number of infected people and an increase in the number of deaths. Studies have shown that psychosomatic aspects in infected patients such as fear of discrimination and stigma, also play a role in disease treatment [21].

Another aspect that attracts attention is the tendency to transmit HIV infection. In the context of cases diagnosed with HIV in the EU / EEA, it has been observed that in recent years, the number of cases registered in heterosexuals has decreased steadily. The resulting conclusion is the need to increase patient compliance with appropriate, correct, and complete treatment for an apparent state of health that gives the patient unstigmatized social integration [22].

Aspects of how this can be achieved, involving deciphering the barriers to successful completion of treatment, or methods of overcoming them, can be found by analyzing the specific behaviors of patients in the context of the disease. 


\section{Models related to the behaviors of patients diagnosed with HIV}

Contemporary models related to the behaviors of patients diagnosed with HIV, on a personal and interpersonal level are generically called cognitive-behavioral theories. These two theories are based on key concepts [23].

- The first concept refers to the behavior that is considered to be mediated through cognition, namely, what we know and think affects the way we act.

- The second concept involves the knowledge that is necessary but not sufficient to produce a change in behavior. An important role is played by perceptions, motivations, abilities, and factors in the social environment [24].

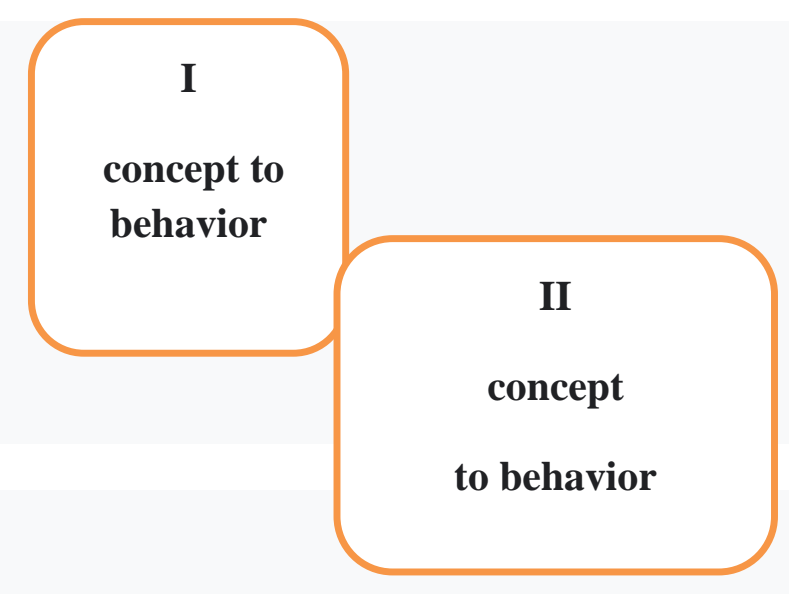

\section{Factors influencing the behavior of the patient diagnosed with HIV}

From a psychological, medical, and ecological perspective, behavior is seen as affecting and being affected by 5 influencing factors: intrapersonal or individual factors, interpersonal factors, institutional, organizational factors, community factors and public policies. From this perspective, a model with three influencing factors can be achieved: individual, interpersonal and community by combining the last three categories of factors. The result is a third category related to broad social structures united under the title of community factors. [25] 
From the information mentioned above, we will selectively make brief references to some important factors to follow in the evaluation of patients diagnosed with HIV.

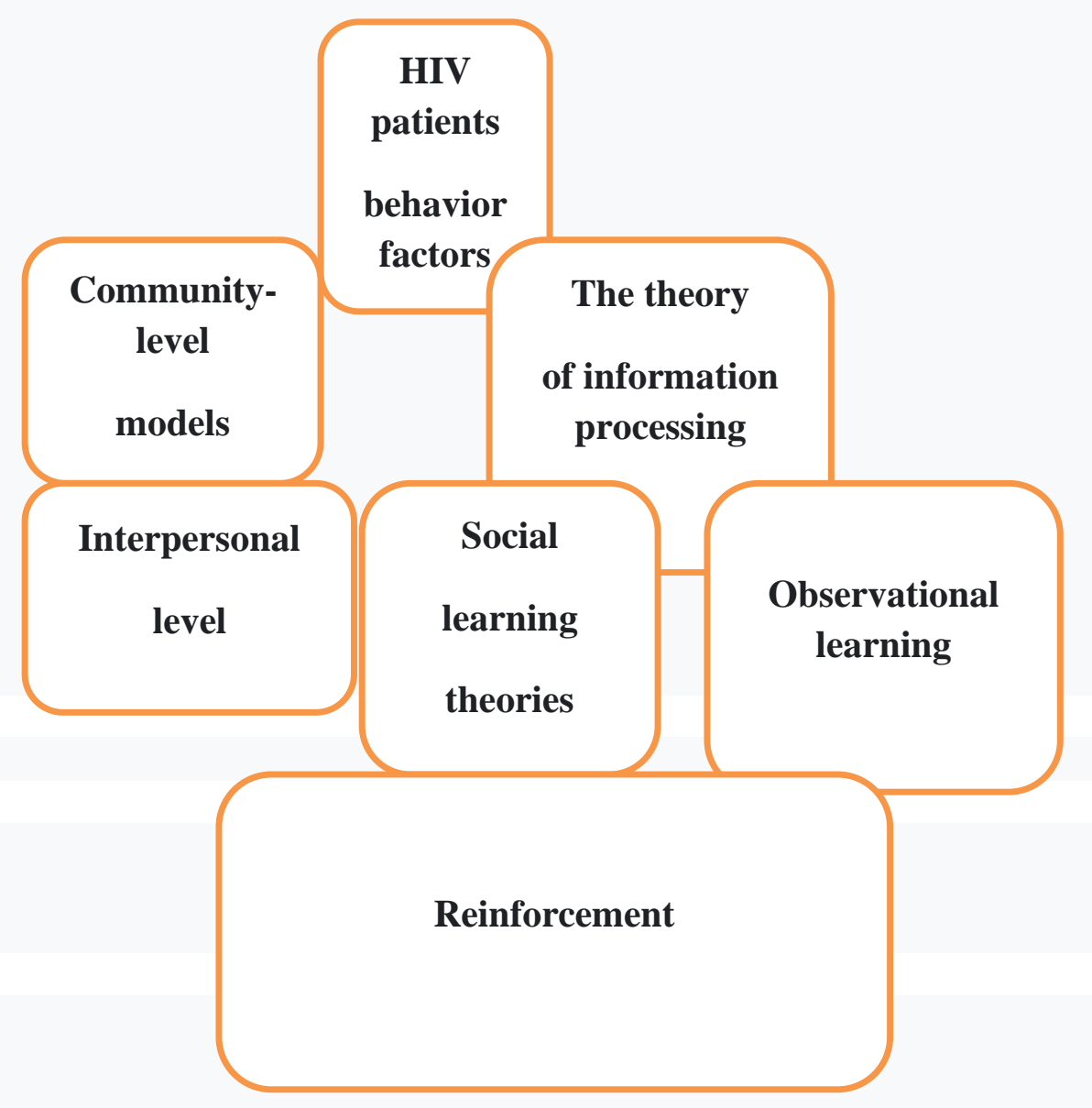

a.Community-level models are essential in implementing the strategies and initiatives of organizations and / or institutions whose missions are to protect and improve health. Such models pay particular attention to the community factors. In this context, collective wellbeing can be achieved by creating structures and policies that support healthy lifestyles and by reducing or eliminating social hazard. However, the models do not have applicability in the field of counseling in order to promote an appropriate behavior towards HIV disease [(26]. 
b.The theory of information processing concerns how information is encoded into memory. This approach has many useful applications in the field of health, implicitly with HIV campaigns [27]. In this context, information is a common tool in health education, essential in substantiating decisions about targeted health promotion. However, often information is useful to any patient, implicitly diagnosed with HIV but it may not be sufficient to encourage healthy behaviors. In this context, HIV patients need guidance in choosing between alternative treatment modalities, specific information related to the hygienic-dietary regime complementary to the specific treatment. Applying this theory, one can follow and analyze how individuals use or fail to use their health information.

c.Interpersonal level theories assume that individuals exist in an environment where the thoughts, advice, assistance, and emotional support of others affect their feelings and behavior. Adopting this means that HIV health promotion interventions should target capacity, motivation, and opportunities within a specific group [28].

d.In an alternative way, models inspired by social learning theories strive to give adequate importance to identifying the environmental conditions that allow the explanation of behaviors, as well as to identify the stages of a possible change [25]. In this context, social learning theories aim at a process of change that occurs in stages, with the target of adopting the specific behavior, implicitly of the patient diagnosed with HIV. The perception of one's own capacity for change refers to the ability of each patient to successfully perform a certain type of action. From this point of view, it is considered the determinant of each individual stigmatized in his or her illness, in this case the diagnosis received by HIV-positive, which changes his behavior [29]. 
e.Observational learning is a type of modeling, embodied in the fact that individuals learn what to expect through the experience of others (30). This approach outlines the usefulness of support groups in counseling HIV patients. New technologies, for example, such as health promotion digital games could be of value in shaping this strategy.

f. Reinforcement is the response to a person's behavior that affects his or her repetition rather than behavior. Positive reinforcement increases the chance of a behavior repeating itself, whereas negative reinforcement leads to behaviors that go unanswered [29] For example, a combination of counseling and reinforcement by educationalists could lead to changes to cognitive behavior among younger people in relation to safe sex practices.

Each of the above social approaches has a role to play in tackling the needs of specific populations, especially strategies orientated at those occupying lower positions in the social hierarchy and young people. By developing the appropriate model to the given situation, greater success should arise in terms of treating more HIV cases and with reducing transmission within the community.

\section{Conclusions}

The global target for 2030 is the elimination of AIDS as a public health problem. To help to meet this goal, it there are the necessary means to succeed in ending the HIV / AIDS epidemic. This is by identifying, treating, and educating the HIV-positive patient. However, the challenge is with reaching the groups where infection and transmission rates are highest. Both nationally and globally, one of the best solutions is to raise awareness of this public health problem is to reach out to different populations. As this paper has set out, those in deprived communities and young people present key targets. In this context, it is necessary to select the appropriate models, 
formulate strategies, and to intensify targeted programs to prevent the transmission of HIV infection, combining medical and social sciences to form a medicosocial approach.

\section{Author Contributions:}

Conceptualization, resources, A.C.; writing — original draft preparation, A.C., T.S; writing-review and editing, A.C., T. S. ; visualization, T.S.;

All authors have read and agreed to the published version of the manuscript.

Funding: This research received no external funding.

Institutional Review Board Statement: Not applicable.

Informed Consent Statement: Not applicable.

Data Availability Statement: Not applicable.

Conflicts of Interest: The authors declare no conflict of interest.

\section{References}

1. Freidson, E., Disability as Social Deviance, in vol. Deviant Behaviour and Social Reaction (Boydell, C., Grindstaff, C., Whitehead, P, - editors), Rinehart and Winston of Canada, Ltd, Montreal, 1972.

2. Glanz, K., Health Behaviour and Health Education. Theory, Research and Practice, Plenum Press, New York, 2002.

3. Guillaume, M., Jennet, M., SIDA, Comment s'en proteger, Question Sante, AIBL, Bruxelles, 1987.

4. Mechanic, D., Medical Sociology: A Comprehensive Text, second edition, The Free Press, New York, 1973.

5. Zack MM, Moriarty DG, Stroup DF, Ford ES, Mokdad AH. Worsening trends in adult healthrelated quality of life and self-rated health - United States, 1993-2001. Public Health Rep 2004; 119: 493. 
6.Hicham T, Ilyas E, Tarik H, et al. Risk factors associated with unsuppressed viral load in HIV1 infected patients at the first antiretroviral therapy in Morocco. Int J Mycobacteriology 2019; 8: 113-117.

7.Xu H, Wang X, Veazey RS. Mucosal immunology of HIV infection. Immunol Rev 2013; 254: 10-33.

8.Mak WW, Poon CY, Pun LY, Cheung SF. Meta-analysis of stigma and mental health. Soc Sci Med 2007; 65: 245-261.

9.Bednasz CJ, Venuto CS, Ma Q, et al. Efavirenz therapeutic range in HIV-1 treatment-naive participants. Ther Drug Monit 2017; 39: 596-603.

10.Wiesner J, Vilcinskas A. Antimicrobial peptides: the ancient arm of the human immune system. Virulence 2010; 1: 440-464.

11.Yang JP, Leu J, Simoni JM, Chen WT, Shiu CS, Zhao H. "Please Don't Make Me Ask for Help": Implicit Social Support and Mental Health in Chinese Individuals Living with HIV. AIDS Behav 2015; 19: 1501-1509.

12.Mostafa MS, Ostovar Z, Danesh E. Comparing social problem solving ability and risk-taking behaviors in patients with AIDS and healthy individuals. Razi Journal of Medical Sciences 2017; 24: $1-8$.

13. Webel AR, Sattar A, Schreiner N, Phillips JC. Social resources, health promotion behavior, and quality of life in adults living with HIV. Appl Nurs Res 2016; 30: 204-209.

14. Webel AR, Wantland D, Rose CD, et al. A cross-sectional relationship between social capital, self-compassion, and perceived HIV symptoms. J Pain Symptom Manag 2015; 50: 59-68.

15. Ferlander S. The importance of different forms of social capital for health. Acta Sociologica 2007; 50: 115-128.

16. Meshkati M, Hajari A, Mostajeran M, Nematolahi S, Mohammadian-Hafshejani-Hafshejani A, Hosseiny L. Knowledge and attitudes of married women referred to health centers affiliated to 
Isfahan University of Medical Sciences, Iran, about AIDS and related factors. Journal of Mazandaran University of Medical Sciences 2014; 23: 100-107.

17.Rafieian M, Parsaeian A. The assessment of risk perception spatial pattern segregated neighborhoods in Yazd city. J Crisis Management 2016: 37-46.

18. Bhattacharya G. Social capital and HIV risks among acculturating Asian Indian men in New York City. AIDS Educ Prev 2005; 17: 555- 567.

19. Kohler HP, Behrman JR, Watkins SC. Social networks and HIV/ AIDS risk perceptions. Demography 2007; 44: 1-33.

20.Jones JC. A study of the association between risk-taking, neighborhood social capital and life satisfaction among adolescent girls. California State University, Sacramento 2013

21. Chalabi M, Mobaraki M. Analysis of the relationship between social capital and crime in the macro and micro levels. Journal of Sociology 2011; 11: 34-57.

22. Golchin M, Haidary AH. Interpersonal violence and social capital in family and school. Social Issues in Iran 2011; 3: 177-212.

23. Arabi M, Rakhshi M, Heidarzadeh M, Ghahramanian A. Knowledge and attitude of female high school students in relation to AIDS in Bonab. Journal of Holistic Nursing And Midwifery 2013; 23: 45-53.

24. Rezaei M, Zakiei A, Reshadat S, Ghasemi SR. The role of individual and personality factors in controlling risky behaviours related to AIDS: proposing a causal model. Personal Ment Health 2017; 11: 51-63.

25. Bhattacharya G. Social capital and HIV risks among acculturating Asian Indian men in New York City. AIDS Educ Prev 2005; 17: 555- 567.

26. Baker, C., Courtney, P., Kubinakova, K. et al Assessing the broader social outcomes of a community health programme through a social-ecological framework, International Journal of Health Promotion and Education 2020, 58 (3): 137-151 
27. Arthur, K., Christofides, N. and Nelson, G. Development of a pre-adolescent inter-generational intervention to address HIV and obesity using intervention mapping, Health Education Journal 2020, 79 (8): 932-947

28. Rubinelli, S. and Diviani, N. The bases of targeting behavior in health promotion and disease prevention, Patient Education and Counseling 2020, 103 (12): 2395-2399

29. Kohler HP, Behrman JR, Watkins SC. Social networks and HIV/ AIDS risk perceptions. Demography 2007; 44: 1-33.

30. Protheroe, J., Estacio, E.V. and Saidy-Khan, S. Patient information materials in general practices and promotion of health literacy: an observational study of their effectiveness, British Journal of General Practice, 2015; 65 (632): e192-e197

WHO, 2003, Global Tuberculosis Control Report, www.who.int

WHO, World Health Report 2005, www.who.int

UNAIDS. Global HIV \& AIDS statistics - 2018 fact sheet; http://www.unaids.org/en/resources/fact-sheet

World Health Organization. Global Health Observatory data repository. Number of new HIV infections. Data by country; http://apps.who.int/gho/data/node.main.HIVINCIDENCE?lang=en,

European Centre for Disease Prevention and Control. HIV/AIDS surveillance in Europe 2017 2016 data; https://ecdc.eu

World Health Organization. Regional Office for Europe. 1 in 2 people living with HIV in Europe is diagnosed late: ECDC and WHO urge improvement in testing practices; http://www.euro.who.int/en/media-centre/sections/press-releases/2017/1-in-2-people-livingwithhiv-in-europe-is-diagnosed-late-ecdc-and-who-urge-improvement-in-testing-practices 40

World Health Organization. HIV/AIDS. Call for examples of differentiated ART delivery for key populations; $\quad$ http://www.who.int/hiv/mediacentre/news/call-examples-differentiatedartdelivery/en/

\section{References for chemical formules}


HIV (GP120) FRAGMENT (421-438)

https://www.chemicalbook.com/ChemicalProductProperty_EN_CB4326609.htm

Compound 1, an inhibitor of HIV-1 integrase generated from within the diversity space by the de novo drug design program.

https://www.researchgate.net/figure/Compound-1-an-inhibitor-of-HIV-1-integrase-generatedfrom-within-the-diversity-space-by_fig4_7687179 